\title{
Association between glycemic control and shift working among healthcare workers with diabetes, Dammam, Saudi Arabia
}

Mona A. Albishri, MD, MSc, Danah M. Alsubaie, MD, MSc, Hassan A. Abugad, MD, AME, Moataza M. Abdel Wahab, PhD, MBCHb.

\begin{abstract}

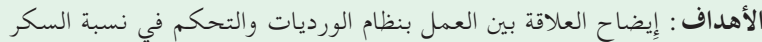

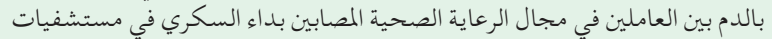

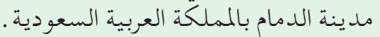

المنهجية : أجريت دراسة مسحية بين العاملين في مجال الرعاية الصحية المصابين

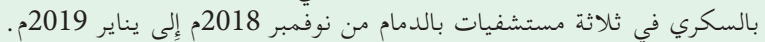

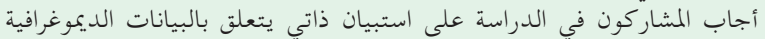

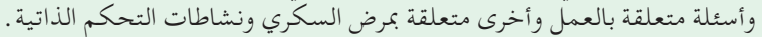

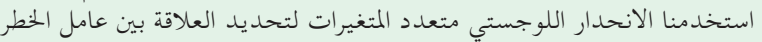

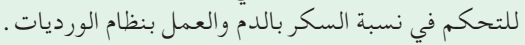

النتائج : تراوحت أعمار المشاركين بين 24 و 60 عاماً. كان متوسط عمر العاملين

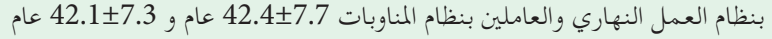

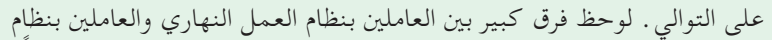

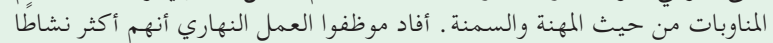

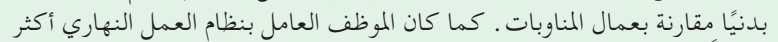

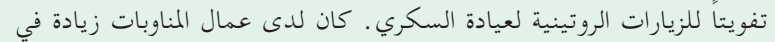

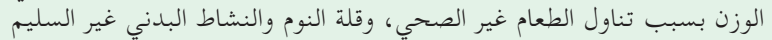

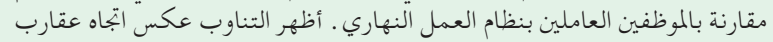

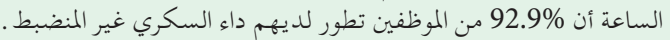

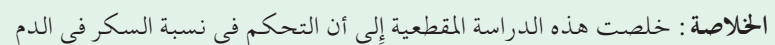

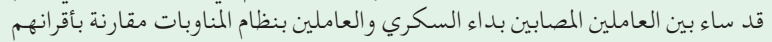
العاملين بنظام العمل النهاري.
\end{abstract}

Objectives: To delineate the relation between shift work and glycemic control among the healthcare workers (HCWs) with diabetes mellitus (DM) in the hospitals of Dammam, Saudi Arabia.

Methods: Across-sectional studywas conducted among HCWs with DM working in 3 hospitals in Dammam, Saudi Arabia, from November 2018 to January 2019. The study participants answered a self-administered questionnaire related to sociodemographic data, work-related questions, diabetes-related questions, the latest hemoglobin $\mathrm{A} 1 \mathrm{C}$ test outcome, and selfmanagement activities. The Chi-square and t-test were used to determine the association between the risk factor of glycemic control and shift work.
Results: The HCW's ages ranged from 24-60 years. The mean age of the employees in the day shift was 42.4 \pm 7.7 years and night shift was $42.1 \pm 7.3$ years. The significant difference between daytime workers and shift workers was observed in terms of occupation, and obesity. Day shift employees reported being significantly more physically active than shift workers. The daily day shift led the employee to miss their routine clinic visits for DM. Shift workers had more weight gain due to unhealthy food intake, sleep deprivation, and improper physical activity when compared with daytime employees. Anti-clockwise shift rotation significantly demonstrated that $92.9 \%$ of employees developed uncontrolled DM.

Conclusion: Glycemic control was worsened among the shift worker with DM compared to daytime workers.

Keywords: shift work schedule, sleep disorders, glycemic control, diabetes mellitus, health personnel

Saudi Med J 2021; Vol. 42 (12): 1296-1301 doi: 10.15537/smj.2021.42.12.20210416

From the Department of Family and Community Medicine, Imam Abdulrahman Bin Faisal University, Dammam, Kingdom of Saudi Arabia.

Received 9th August 2021. Accepted 18th October 2021.

Address correspondence and reprint request to: Dr. Mona $A$. Albishri, Department of Family and Community Medicine, Imam Abdulrahman Bin Faisal University, Dammam, Kingdom of Saudi Arabia.E-mail:monaalbsehri@gmail.com

ORCID ID: https:orcid.org/0000-0002-5886-3023

Disclosure. Authors have no conflict of interests, and the work was not supported or funded by any drug company. 
$\mathrm{A}^{\mathrm{l}}$ lthough no standard definition of "shift work" is available, shift work term is usually used to describe the work scheduled outside the standard working hours. ${ }^{1}$ The working shift is essential and inevitable in many sectors willing to provide 24-hour continuous services. ${ }^{2}$ It is estimated that the prevalence of shift work has increased approximately 27\% in the United States in recent years. ${ }^{3}$ Previous studies reported an association between shift work and chronic illnesses like diabetes mellitus (DM), cardiovascular diseases (CVDs), obesity, and cancer. ${ }^{4,5}$ However, this association was also linked to other factors like lifestyle changes, social stress, job changes, and circadian rhythm impairment. ${ }^{6,7}$

Diabetes mellitus is a significant public healthrelated problem. The World Health Organization (WHO) stated that more than 400 million individuals are living with DM worldwide with approximately 1.6 million recorded deaths every year. ${ }^{8,9}$

The prevalence of DM in Saudi Arabia is rapidly increasing at an alarming rate over the past few years. It has affected approximately $20 \%$ of the adult population. The prevalence rate is expected to increase further and exceed more than $40 \%$ of the adult population by 2030. . $^{10,11}$

Diabetes mellitus is a metabolic disorder that causes a rise in blood glucose levels. The risk factors of DM are obesity, increasing age, family history, smoking, and physical inactivity. These risk factors reported emerging evidence about the relationship between circadian misalignment and glucose intolerance. ${ }^{12}$ The literature suggests that shift work is associated with several healthrelated issues including diabetes. One study reported that midnight workers devour higher calories food when compared with fixed day employees. ${ }^{13}$ Similarly, another researcher reported an association between shift work and the development of abdominal obesity. ${ }^{14}$ The incidence of DM is higher among shift workers due to sleep deprivation, a recognized risk factor for diabetes. ${ }^{15}$ A cross-sectional study of 95 patients with type-2 DM working in one of the Brazilian hospitals was divided into 2 groups, namely, day and night shifts. This study suggested insulin resistance is responsible of causing larger waist circumference among the workers on the night shift. ${ }^{16}$

Similarly, another cross-sectional study of 27,485 employers in Sweden stated lower high-density lipoprotein (HDL) cholesterol concentration, high triglyceride level, and increased obesity among the night shift workers than day shift workers. This study suggested a potential association between shift work and DM. ${ }^{17}$ Also, the outcome of a recent study signifies the negative impact on postprandial triglyceride responses and insulin sensitivity after the rotational period of night shift. ${ }^{18}$

This cross-sectional study aims to observe and outline the association between shift work and DM among HCWs in Dammam hospitals of Saudi Arabia. This study compares day shift and night shift effects on diabetic control by assessing hemoglobin A1C (HbAlc), sleep, physical activities, and diet.

Methods. A cross sectional study was carried out among diabetic healthcare workers (namely: doctors, nurses, pharmacists, technicians, and administrators). These employees were diagnosed at their employee health clinics. The study was carried of from November 2018 to January 2019 at 3 hospitals in Dammam, Saudi Arabia (Dammam Medical Complex [DMC], Maternity and Children Hospital [MCH], and Alamal Hospital). The total number of HCWs in these hospitals was 6700 (DMC: 3,100, MCH: 2,600, and Alamal Hospital: 1,000$)$. The sample size was calculated to be 365 using Epi Info ${ }^{\text {tM }}$ at $95 \%$ confidence level, 50\% expected frequency, and $4.5 \%$ acceptable margin of error. ${ }^{19}$ The study was performed in these 3 hospitals to make the findings more generalize as each hospital provides a different medical service from the others. This study involves volunteers participation and is ready to provide $100 \%$ response until the study ends.

The inclusion criteria were HCWs with DM, male or female, working either in irregularly alternating shifts or exclusively in morning shifts who have had recently performed $\mathrm{HbAlc}$ test in the preceding 3 months. Healthcare workers who were diagnosed with DM in less than one year and those working less than 3 night shifts per month were excluded.

The HbAlc level of participants was grouped as controlled (HbAlclevel $<7 \%$ ) and uncontrolled ( $\mathrm{HbAlc}$ level $\geq 7 \%$ ). Also, the participants were categorized into 3 groups: fixed day shift employees (working hours: 07:00-15:00 hours), evening shift employees (working hours: 15:00-23:00 hours), and night shift employees (working hours: 23:00-07:00 hours) based on their latest 3-month working shifts. The study includes HCWs with clockwise or counterclockwise rotation of shift work. Participants were selected by the convenience sampling technique and the analysis was not started until achieving the required sample size target of 365 . The study participants answered a self-administered questionnaire related to sociodemographic data (4 items), work-related questions (4 items), diabetesrelated questions, latest HbAlc test outcome and selfmanagement activities includs being physically active, bringing healthy food to the workplace, and keeping 
regular DM clinic follow-up visits (6 items). The questionnaire is validated by consulting 3 consultants specialized in occupational health. To further test the questionnaire validity, a pilot study was conducted on $10 \mathrm{HCW}$ with DM, who were excluded later from the study sample. The clarity of some questionnaire items needed for modifications were completed in light of the pilot study results.

Assessments of physical activity and healthy diet in this study are based on the definitions and recommendations of WHO. The World Health Organization recommends that adults should undertake physical activity and should aim to achieve at least 150 minutes of moderate-intensity or equivalent per week. ${ }^{20}$ Daily healthy diet is defined, based on the WHO recommendations, as consuming more than 400 grams of vegetables and fruits, $<30 \%$ fat intake of total energy intake, and $<10 \%$ free sugar of total energy intake and consuming $<5$ grams of salt per day. ${ }^{21}$ While good quality sleep is defined as person's perception of falling asleep easily after getting into bed with sufficient sleep duration (not less than 7 hours) along without complaints of sleepiness during the day. ${ }^{22}$

The Department of Research and Studies at the General Health Affairs at the Eastern Region, Saudi Ministry of Health, Saudi Arabia, gave the ethical clearance to conduct this study. All participants were assured confidentiality and provided informed consent for participation in this study.

Statistical analysis. Demographic, occupational, and lifestyle characteristics distribution were compared with employees of day shift and night shift at $95 \%$ confidence level and 5\% significance level by using descriptive and inferential statistics. Descriptive statistics was used for continuous outcome variables. Analysis was carried out to determine the variables that are independently and significantly correlated to the HbA1c. Chi-square and t-test were used to assess the factors associated with DM for categorical variables and numeric data. Multivariate analysis was performed using logistic regression with diabetic control as the dependent variable and independent factors. Data was analyzed by using Statistical Package for the Social Sciences for Windows, version 25.0 (IBM Corp., Armonk, NY, USA).

Results. Baseline characteristics of this crosssectional study are reported in Table 1 . The participant's ages ranged from 24-60 years. The mean age of the employees in the day shift was $42.4 \pm 7.7$ years and night shifts was $42.1 \pm 7.3$ years. The study population consisted of $53.2 \%$ of male and $46.8 \%$ female workers. Similarly, the study enrolled $45.4 \%$ nurses,
$16.5 \%$ technicians, and $8.1 \%$ physicians. Most of the employees were married $(65.7 \%)$, followed by single (21.1\%), and divorced (13.2\%). Most of the employees worked as shift workers $(59.7 \%)$, followed by day shift employees $(40.3 \%)$. Less than a quarter of employees had counterclockwise rotation $(12.7 \%)$, while the rest had clockwise shift work (87.3\%).

An independent student t-test and Chi-square tests were conducted to compare daytime workers and shift workers' age, gender, occupation, and marital status. The analysis reported a significant difference between daytime workers and shift workers in terms of occupation. Also, the study demonstrated no significant association of age, gender, and marital status between daytime workers and shift workers. Most of the employees were obese $(91.0 \%)$, body mass index (BMI) of more than $25 \mathrm{~kg} / \mathrm{m}^{2}$. Chi-square test compared diabetes-related questions (namely, BMI, smoking status, and latest $\mathrm{HbA1c}$ ) between daytime and shift workers. This study significantly observed higher BMI among shift workers than day workers. There was no significant difference between daytime workers and shift workers in smoking $\left(\mathrm{x}^{2}=1.97 ; p=0.162\right)$.

Most of the participants (42.4\%) reported moderate exercise for $<150$ minutes per week, followed by $42.4 \%$ of participants with no exercise, and $26.2 \%$ of participants reported extreme exercise for $>150$ minutes per week. Only $29.7 \%$ of employees reported routine visits of DM clinic, $48.3 \%$ of employees reported occasional routine visits while $21.8 \%$ employees were completely missing their follow-up visits. Day shift employees reported being more physically active than shift workers, and the outcome was statistically significant $(p<0.05)$. Also, day workers significantly missed their routine visits for DM clinics compared with shift workers. The Chi-square test compared the quality and duration of sleep, and dietary food among day and shift workers. The analysis significantly reported that frequency and quality of lousy sleep were higher among shift workers by $49.8 \%$ than daytime workers. Similarly, the analysis reported frequency of healthy dietary foods was significantly higher by $52.3 \%$ among daytime workers than shift workers.

The mean age of the employees in the controlled group was $42.7 \pm 7.2$ years and uncontrolled group was $41.7 \pm 7.6$ years. The Chi-square analysis demonstrated significant uncontrolled HbA1c in $60.6 \%$ of employees on shift work and $30.2 \%$ of employees in the daytime. In addition to this, anti-clockwise shift rotation significantly demonstrated that $92.9 \%$ of employees develop uncontrolled HbA1c. Moreover, employees with normal BMI significantly demonstrated $81.8 \%$ 
Table 1 - Descriptive statistics for respondents' work type and glycemic control according to sociodemographic, diabetes related questions, self-management activities, sleep and diet.

\begin{tabular}{|c|c|c|c|c|c|c|c|c|c|}
\hline \multirow[t]{3}{*}{ Characteristics } & \multirow[t]{3}{*}{ Shift work $(n=221)$} & \multirow{3}{*}{$\begin{array}{l}\text { Daytime work }(\mathrm{n}=149) \\
\mathrm{n}(\%)\end{array}$} & \multirow[t]{3}{*}{ Total } & \multirow[t]{3}{*}{ Test of sig. } & \multirow[t]{3}{*}{$P$-value } & \multicolumn{2}{|c|}{ HbA1c \% } & \multirow[t]{3}{*}{ Test of sig. } & \multirow[t]{3}{*}{$P$-value } \\
\hline & & & & & & Controlled & Uncontrolled & & \\
\hline & & & & & & \multicolumn{2}{|c|}{$\mathbf{n}(\%)$} & & \\
\hline Age, mean $\pm S D$ & $42.1 \pm 7.3$ & $42.4 \pm 7.7$ & & $\mathrm{t}$-test $=0.406$ & 0.685 & $42.7 \pm 7.2$ & $41.7 \pm 7.6$ & $\mathrm{t}$-test $=1.3$ & 0.190 \\
\hline \multicolumn{10}{|l|}{ Gender } \\
\hline $\begin{array}{l}\text { Male } \\
\text { Female }\end{array}$ & $\begin{array}{l}114(51.6) \\
107(48.4)\end{array}$ & $\begin{array}{l}83(55.7) \\
66(44.3)\end{array}$ & $\begin{array}{l}197(53.2) \\
173(46.8)\end{array}$ & $x^{2}=0.607$ & 0.436 & $\begin{array}{c}100(50.8) \\
91(52.6)\end{array}$ & $\begin{array}{l}97(49.2) \\
82(47.4)\end{array}$ & $x^{2}=0.125$ & 0.724 \\
\hline \multicolumn{10}{|l|}{ Occupation } \\
\hline $\begin{array}{l}\text { Doctor } \\
\text { Nurse } \\
\text { Technician } \\
\text { Other }\end{array}$ & $\begin{array}{c}19(8.6) \\
124(56.1) \\
41(18.6) \\
37(16.7)\end{array}$ & $\begin{array}{l}11(7.4) \\
44(29.5) \\
20(13.4) \\
74(49.7)\end{array}$ & $\begin{array}{c}30(8.1) \\
168(45.4) \\
61(16.4) \\
111(30)\end{array}$ & $x^{2}=47.58$ & 0.001 & $\begin{array}{l}17(56.7) \\
78(46.4) \\
30(49.2) \\
66(59.5)\end{array}$ & $\begin{array}{l}13(43.3) \\
90(53.6) \\
31(50.8) \\
45(40.5)\end{array}$ & $x^{2}=4.99$ & 0.172 \\
\hline \multicolumn{10}{|l|}{ Marital status } \\
\hline $\begin{array}{l}\text { Single } \\
\text { Married } \\
\text { Other }\end{array}$ & $\begin{array}{c}53(24) \\
140(63.3) \\
28(12.7)\end{array}$ & $\begin{array}{c}25(16.9) \\
103(69.1) \\
21(14.1)\end{array}$ & $\begin{array}{c}78(21.1) \\
243(65.7) \\
49(13.2)\end{array}$ & $x^{2}=2.779$ & 0.249 & $\begin{array}{c}32(41) \\
135(55.6) \\
42(49)\end{array}$ & $\begin{array}{c}46(59) \\
108(44.4) \\
25(51)\end{array}$ & $x^{2}=5.149$ & 0.076 \\
\hline \multicolumn{10}{|l|}{ BMI category } \\
\hline $\begin{array}{l}18-24.99 \\
25-29.99 \\
>30\end{array}$ & $\begin{array}{c}17(7.7) \\
111(50.2) \\
93(42.1)\end{array}$ & $\begin{array}{l}16(10.7) \\
92(60.7) \\
41(27.5)\end{array}$ & $\begin{array}{c}33(8.9) \\
203(54.8) \\
134(36.2)\end{array}$ & $\mathrm{x}^{2}=8.29$ & 0.016 & $\begin{array}{c}27(81.8) \\
116(57.1) \\
48(35.8)\end{array}$ & $\begin{array}{c}6(18.2) \\
87(42.9) \\
86(64.2)\end{array}$ & $\mathrm{x}^{2}=27.9$ & 0.001 \\
\hline \multicolumn{10}{|l|}{ Smoking } \\
\hline $\begin{array}{l}\text { Yes } \\
\text { No }\end{array}$ & $\begin{array}{c}63(28.7) \\
158(71.3)\end{array}$ & $\begin{array}{l}52(34.9) \\
97(65.1)\end{array}$ & $\begin{array}{l}115(31.1) \\
255(68.9)\end{array}$ & $x^{2}=1.97$ & 0.162 & $\begin{array}{c}57(50) \\
134(52.3)\end{array}$ & $\begin{array}{c}57(50) \\
122(47.7)\end{array}$ & $\mathrm{x}^{2}=0.173$ & 0.677 \\
\hline Physical activity & per week & & & & & & & & \\
\hline $\begin{array}{l}>150 \mathrm{~min} \\
<150 \mathrm{~min} \\
\text { None }\end{array}$ & $\begin{array}{c}42(19) \\
98(44.3) \\
81(36.7)\end{array}$ & $\begin{array}{l}55(36.9) \\
59(39.6) \\
35(23.5)\end{array}$ & $\begin{array}{l}97(26.2) \\
157(42.4) \\
116(31.3)\end{array}$ & $x^{2}=16.27$ & 0.001 & $\begin{array}{l}69(71.1) \\
79(50.3) \\
43(37.1)\end{array}$ & $\begin{array}{l}28(28.9) \\
78(49.7) \\
73(62.9)\end{array}$ & $x^{2}=24.7$ & 0.001 \\
\hline Missing regular & routine visits in diabe & tes clinic & & & & & & & \\
\hline $\begin{array}{l}\text { Yes } \\
\text { No } \\
\text { Sometimes }\end{array}$ & $\begin{array}{c}62(28.1) \\
52(23.5) \\
107(48.4)\end{array}$ & $\begin{array}{l}19(12.8) \\
58(38.9) \\
72(48.3)\end{array}$ & $\begin{array}{l}81(21.8) \\
110(29.7) \\
179(48.3)\end{array}$ & $x^{2}=16.6$ & 0.001 & $\begin{array}{l}32(39.5) \\
71(64.5) \\
88(49.2)\end{array}$ & $\begin{array}{l}49(60.5) \\
39(35.5) \\
91(50.8)\end{array}$ & $x^{2}=12.55$ & 0.002 \\
\hline Night sleeping ho & ours & & & & & & & & \\
\hline $\begin{array}{l}<7 \text { hours } \\
7-9 \text { hours } \\
>9 \text { hours }\end{array}$ & $\begin{array}{l}166(75.1) \\
30(13.6) \\
25(11.3)\end{array}$ & $\begin{array}{l}94(63.1) \\
50(33.6) \\
5(3.4)\end{array}$ & $\begin{array}{l}260(70.2) \\
80(21.6) \\
30(8.1)\end{array}$ & $x^{2}=25.22$ & 0.001 & $\begin{array}{l}125(48.1) \\
51(63.8) \\
15(50)\end{array}$ & $\begin{array}{l}135(51.9) \\
29(36.2) \\
15(50)\end{array}$ & $x^{2}=6.05$ & 0.049 \\
\hline Sleep quality & & & & & & & & & \\
\hline $\begin{array}{l}\text { Good } \\
\text { Bad }\end{array}$ & $\begin{array}{l}111(50.2) \\
110(49.8)\end{array}$ & $\begin{array}{c}104(69.8) \\
45(30.2)\end{array}$ & $\begin{array}{l}215(58.1) \\
155(41.8)\end{array}$ & $x^{2}=14.25$ & 0.001 & $\begin{array}{l}136(63.3) \\
55(35.5)\end{array}$ & $\begin{array}{c}79(36.7) \\
100(64.5)\end{array}$ & $x^{2}=27.8$ & 0.001 \\
\hline Diet & & & & & & & & & \\
\hline $\begin{array}{l}\text { Healthy } \\
\text { Less healthy } \\
\text { Unhealthy }\end{array}$ & $\begin{array}{l}50(22.6) \\
114(51.6) \\
57(25.8)\end{array}$ & $\begin{array}{l}78(52.3) \\
55(36.9) \\
16(10.7)\end{array}$ & $\begin{array}{l}128(34.5) \\
169(45.6) \\
73(19.7)\end{array}$ & $x^{2}=37.15$ & 0.001 & $\begin{array}{l}108(84.4) \\
77(45.6) \\
6(8.2)\end{array}$ & $\begin{array}{l}20(15.6) \\
92(54.5) \\
67(91.6)\end{array}$ & $x^{2}=112.5$ & 0.001 \\
\hline
\end{tabular}

sig: significant, HbA1c: hemoglobin A1C, SD: standard deviation, BMI: body mass index, min: minutes

of controlled and $18.2 \%$ of uncontrolled HbA1c levels. The obese employee reported a high degree of uncontrolled HbA1c level $\left(\mathrm{x}^{2}=27.9 ; p=0.001\right)$.

Improper physical activity, missing regular follow-up, and low duration and lousy sleep quality were significantly higher among the uncontrolled group than the control group. This study reported that Alamal Hospital staff had significantly more controlled HbA1c followed by DMC and MCH. Similarly, MCH staff had significantly more uncontrolled $\mathrm{HbA1c}$ than DMC and Alamal Hospital. The effect of the nature of diet had a linkage with diabetic control. Most of the participants having healthy diets $(84.4 \%)$ had controlled diabetes. Similarly, the majority of participants with unhealthy diets $(91.6 \%)$ had uncontrolled diabetes. Other factors like age, gender, marital status, occupation, and smoking history had no significant association with the control of diabetes, as shown in Table 1. 
Multiple regression analyzed the effects of factors like work type (day/shift), occupation, hospital, BMI, physical activity, regular follow up visits, and sleep quality and duration on diabetic control. However, few factors like work type, hospital, dietary food, and BMI of the employees significantly affected diabetic control as described in Table 2. According to this study, a good diabetic control method was associated with routine daywork, a healthy diet, and an average BMI. Moreover, working in Alamal Hospital was associated with well-controlled DM.

Discussion. This study observed that shift work (39.4\%) was significantly associated with worse diabetic control among employees with DM than daytime work (60.6\%). These findings had a similar agreement with a study evaluating insulin resistance, reporting that shift workers had developed insulin resistance more frequently than daytime workers. ${ }^{23}$

Logistic regression suggested that obesity and unhealthy dietary foods had a negative effect on glycemic control. Similarly, it demonstrated that shift work has a negative influence on diabetes control. For patients with DM, such work schedule requires adjusting mealtimes and insulin dosing schedule without triggering hypoglycemia episodes, which may account for their worse glycemic control. ${ }^{5}$

Our study reported that obesity rates in shift workers was $92.03 \%$ and daytime worker was $27.5 \%$. These findings agreed with a survey conducted by El Tayeb et al, ${ }^{1}$ who reported that the shift work group had significantly higher BMI when compared to the daytime work group. The shift work increases weight gain and the rising prevalence of DM. Shift work differs with food availability during routine daytime work, resulting in eating snacks, high-fat food, and weight gain. ${ }^{5}$

Also, shift work negatively affects the nutritional need of the body. Our study demonstrated that $77.4 \%$ of HCWs have uncontrolled DM due to unhealthy food. This finding was in accordance with a crosssectional study where the night shift workers had the highest calorie intake. ${ }^{13}$ Similarly, Manodpitipong et $\mathrm{al},{ }^{24}$ revealed that night shift employees had considerably greater daily calorie consumption than other groups, which might lead to a higher BMI in a long term.

Our findings suggest that the shift worker was significantly less physically active than the daytime worker. Another study conducted in Poland in 2014 revealed that rotating night shift nurses and midwives had considerably lower exercise levels than those working solely during the day. ${ }^{25}$ Exercise improves glucose regulation by improving insulin sensitivity and non-insulin-dependent glucose uptake in skeletal muscle. ${ }^{26}$

Alamal Hospital, a psychiatric hospital, had the best controlled DM workers, which might be reflecting low work stress level, optimal workers to patient's ratio, flexible working schedule, and the presence of DM specialists in the hospital employee clinic.

Study limitations. The recall bias of the last 3 months of $\mathrm{HbAlc}$ reading, subjective assessment of sleep, nature of the sampling technique used, and unavailability of data on nationality (Saudi and non-Saudi). In addition, the study was carried out in one city in the country, and may not be fully generalizable to other places. Despite these limitations, the study provides an important evaluation of multiple factors (HbA1c, sleep, diet, and self-management activity) in HCWs with DM in the day and shift work.

Table 2 - Multiple regression analysis of variables controlling diabetes.

\begin{tabular}{|c|c|c|c|c|c|c|c|c|}
\hline \multirow[t]{2}{*}{ Variables } & \multirow[t]{2}{*}{ B } & \multirow[t]{2}{*}{ S.E. } & \multirow[t]{2}{*}{ Wald } & \multirow[t]{2}{*}{ Df } & \multirow[t]{2}{*}{ Sig. } & \multirow[t]{2}{*}{ Adj OR } & \multicolumn{2}{|c|}{$95 \%$ CI for adj OR } \\
\hline & & & & & & & Lower & Upper \\
\hline Working in shifts & 3.131 & 0.571 & 30.032 & 1 & $>0.001$ & 22.888 & 7.471 & 70.126 \\
\hline Psychiatry (ref) & & & 49.967 & 2 & $>0.001$ & & & \\
\hline $\mathrm{DMC}$ & 3.776 & 0.635 & 35.327 & 1 & $>0.001$ & 43.645 & 12.565 & 151.606 \\
\hline $\mathrm{MCH}$ & 2.692 & 0.430 & 39.154 & 1 & $>0.001$ & 14.760 & 6.352 & 34.300 \\
\hline Healthy diet (ref) & & & 48.079 & 2 & $>0.001$ & & & \\
\hline Less healthy diet & 1.849 & 0.354 & 27.251 & 1 & $>0.001$ & 6.353 & 3.173 & 12.719 \\
\hline Unhealthy diet & 3.783 & 0.578 & 42.828 & 1 & $>0.001$ & 43.953 & 14.156 & 136.475 \\
\hline BMI & 0.122 & 0.051 & 5.774 & 1 & 0.016 & 1.130 & 1.023 & 1.248 \\
\hline Constant & -8.324 & 1.827 & 20.760 & 1 & $>0.001$ & 0.000 & & \\
\hline
\end{tabular}

B: coefficient, S.E: standard error, Wald: Wald test, Df: degrees of freedom, Ref: reference, Sig: significant, Adj: adjust, OR: odd ratio, CI: confidence interval, DMC: Dammam Medical Complex, MCH: Maternity and Children Hospital, BMI: body mass index 
In conclusion, glycemic control was worsened among the shift workers with DM compared to daytime workers. Shift work was linked with shorter and lousy sleep patterns, reduced physical activity, and decreased adherence to self-management activities. In addition, the study revealed that the anti-clockwise shifting schedule had the worst impact on controlling DM. Healthcare institutions should have a mechanism to identify staff with DM working in irregularly alternating shifts along with adaptation programs including availability of DM specialists in the hospital employee clinic.

Acknowledgment. The authors gratefully acknowledge XPERIA Professional Writer for English language editing.

\section{References}

1. El Tayeb IM, El Saghier EOA, Ramadan BK. Impact of shift work of glycemic control in insulin treated diabetic Dar El Chefa hospital, Egypt 2014. Int J Diabetes Res 2014; 3: 15-21.

2. Kautzky-Willer A, Harreiter J, Pacini G. Sex and gender differences in risk, pathophysiology and complications of type 2 diabetes mellitus. Endocr Rev 2016; 37: 278-316.

3. Yong LC, Li J, Calvert GM. Sleep-related problems in the US working population: prevalence and association with shiftwork status. Occup Environ Med 2017; 74: 93-104.

4. Rivera AS, Akanbi M, O’Dwyer LC, McHugh M. Shift work and long work hours and their association with chronic health conditions: a systematic review of systematic reviews with metaanalyses. PLoS One 2020; 15: e0231037.

5. Young J, Waclawski E, Young JA, Spencer J. Control of type 1 diabetes mellitus and shift work. Occup Med (Lond) 2013; 63: 70-72.

6. Szosland D. Shift work and metabolic syndrome, diabetes mellitus and ischaemic heart disease. Int J Occup Med Environ Health 2010; 23: 287-2891.

7. Frost P, Kolstad HA, Bonde JP. Shift work and the risk of ischemic heart disease - a systematic review of the epidemiologic evidence. Scand J Work Environ Health 2009; 35: 163-179.

8. World Health Organization. World health statistics 2019: monitoring health for the SDGs, sustainable development goals. [Updated 2019; Accessed 2020 January 12]. Available from: https://www.who.int/publications/i/item/world-healthstatistics-2019-monitoring-health-for-the-sdgs-sustainabledevelopment-goals

9. Knutsson A, Kempe A. Shift work and diabetes--a systematic review. Chronobiol Int 2014; 31: 1146-1151.

10. Al Dawish MA, Robert AA, Braham R, Al Hayek AA, Al Saeed A, Ahmed RA, et al. Diabetes mellitus in Saudi Arabia: a review of the recent literature. Curr Diabetes Rev 2016; 12: 359-368.

11. Robert AA, Al Dawish MA. The worrying trend of diabetes mellitus in Saudi Arabia: an urgent call to action. Curr Diabetes Rev 2020; 16: 204-210.
12. Buxton OM, Cain SW, O'Connor SP, Porter JH, Duffy JF, Wang W, et al. Adverse metabolic consequences in humans of prolonged sleep restriction combined with circadian disruption. Sci Transl Med 2012; 4: 129ra43.

13. Morikawa Y, Miura K, Sasaki S, Yoshita K, Yoneyama S, Sakurai $\mathrm{M}$, et al. Evaluation of the effects of shift work on nutrient intake: a cross-sectional study. J Occup Health 2008; 50: 270-278.

14. Guo Y, Liu Y, Huang X, Rong Y, He M, Wang Y, et al. The effects of shift work on sleeping quality, hypertension and diabetes in retired workers. PLoS One 2013; 8: e71107.

15. Reutrakul S, Knutson KL. Consequences of circadian disruption on cardiometabolic health. Sleep Med Clin 2015; 10: 455-468.

16. Karlsson B, Knutsson A, Lindahl B. Is there an association between shift work and having a metabolic syndrome? Results from a population based study of 27,485 people. Occup Environ Med 2001; 58: 747-752.

17. Rodrigues TC, Canani LH. [The influence of the work shift in patients with type 2 diabetes]. Rev Assoc Med Bras (1992) 2008; 54: 160-162. [in Portuguese]

18. Sharma A, Laurenti MC, Dalla Man C, Varghese RT, Cobelli C, Rizza RA, et al. Glucose metabolism during rotational shift-work in healthcare workers. Diabetologia 2017; 60: 1483-1490.

19. Centers for Disease Control and Prevention. Epi Info ${ }^{\mathrm{TM}}$, a database and statistics program for public health professionals. 2011. [Updated 2021; Accessed 2021 March 15]. Available from: https://www.cdc.gov/epiinfo/index.html

20. World Health Organization T. Global recommendations on physical activity for health. [Updated 2010; Accessed 2020 January 17]. Available from: https://www.who.int/ dietphysicalactivity/global-PA-recs-2010.pdf

21. World Health Organization. Healthy Diet: Key Facts. [Updated 2020; Accessed 2020 May 15]. Available from: https://www. who.int/news-room/fact-sheets/detail/healthy-diet

22. Landry GJ, Best JR, Liu-Ambrose T. Measuring sleep quality in older adults: a comparison using subjective and objective methods. Front Aging Neurosci 2015; 7: 166.

23. Akour A, Farha RA, Alefishat E, Kasabri V, Bulatova N, Naffa $\mathrm{R}$. Insulin resistance and levels of cardiovascular biomarkers in night-shift workers. Sleep and Biological Rhythms 2017; 15: 283-290.

24. Manodpitipong A, Saetung S, Nimitphong H, Siwasaranond N, Wongphan T, Sornsiriwong C, et al. Night-shift work is associated with poorer glycaemic control in patients with type 2 diabetes. J Sleep Res 2017; 26: 764-772.

25. Peplonska B, Bukowska A, Sobala W. Rotating night shift work and physical activity of nurses and midwives in the crosssectional study in Łódź, Poland. Chronobiol Int 2014; 31: 1152-1159.

26. Fritzen AM, Domingo-Espín J, Lundsgaard AM, Kleinert M, Israelsen I, Carl CS, et al. ApoA-1 improves glucose tolerance by increasing glucose uptake into heart and skeletal muscle independently of AMPK $\alpha 2$. Mol Metab 2020; 35: 100949. 